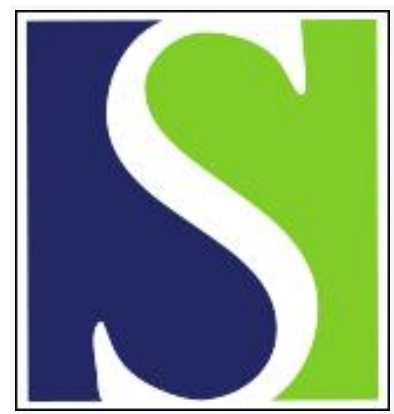

Scand J Work Environ Health 2020;46(4):429-436

https://doi.org/10.5271/sjweh.3884

Published online: 16 Jan 2020, Issue date: 01 Jul 2020

The effect of training for a participatory ergonomic intervention on physical exertion and musculoskeletal pain among childcare workers (the TOY project) - a wait-list cluster-randomized controlled trial

by Rasmussen CDN, Sørensen $\mathrm{OH}$, van der Beek AJ, Holtermann A

Surprisingly little research has been conducted on childcare work. This study contributes to closing the research gap of lack of research for this occupational group. The 20-week workplace participatory ergonomic intervention among childcare workers was both feasible and effective in reducing musculoskeletal pain-related sickness absence and is thereby beneficial for society.

Affiliation: National Research Centre for the Working Environment, Lersø Parkallé 105, 2100 Copenhagen Ø, Denmark. cnr@nfa.dk

Refers to the following texts of the Journal: 2011;37(5):383-393

2012;38(4):314-326 2012;38(6):582-589 2016;42(3):192-200

2017;43(6):526-539 2018;44(2):111-112 2019;45(4):356-369

The following article refers to this text: $2022 ; 48(8): 651-661$

Key terms: childcare; childcare worker; cluster-randomized controlled trial; ergonomic; ergonomic intervention; intervention; MSD; musculoskeletal; musculoskeletal disease; musculoskeletal disorder; musculoskeletal pain; physical exertion; randomized controlled trial; RCT; sickness absence; sickness absence; TOY project; training; wait-list; workplace intervention

This article in PubMed: www.ncbi.nlm.nih.gov/pubmed/31945165

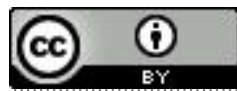




\title{
The effect of training for a participatory ergonomic intervention on physical exertion and musculoskeletal pain among childcare workers (the TOY project) - a wait-list cluster-randomized controlled trial
}

\author{
by Charlotte Diana Nørregaard Rasmussen, PhD, ${ }^{1}$ Ole Henning Sørensen, PhD, ${ }^{1,2}$ Allard J van der Beek, PhD, ${ }^{2}$ Andreas \\ Holtermann, PhD ${ }^{1}$
}

\begin{abstract}
Rasmussen CDN, Sørensen OH, van der Beek A, Holtermann A. The effect of training for a participatory ergonomic intervention on physical exertion and musculoskeletal pain among childcare workers (the TOY project) - a wait-list cluster-randomized controlled trial. Scand J Work Environ Health. 2020;46(4):429-436. doi:10.5271/sjweh.3884
\end{abstract}

\begin{abstract}
Objective Many employees have high physical exertion at work and suffer from musculoskeletal pain (MSP) leading to sickness absence with large costs. Participatory ergonomics is a potentially effective intervention for reducing physical exertion, MSP and sickness absence. The main aim of this study was to investigate the effectiveness of a 20-week workplace participatory ergonomic intervention among childcare workers on physical exertion and MSP.
\end{abstract}

Methods In a two-arm cluster-randomized trial, 190 workers were recruited from 16 childcare institutions and randomly assigned to either a 20 -week participatory ergonomics intervention consisting of three training workshops or a control group receiving usual care. Primary outcomes were physical exertion during work, maximal pain intensity, number of pain regions, and pain-related work interference. Secondary outcomes were MSPrelated sickness absence, need for recovery (NFR), employee involvement, and self-efficacy. We followed the intention-to-treat principle and adhered to the registered study protocol (ISRCTN10928313).

Results After 20 weeks, half the workers noticed some positive changes in their work. However, there were no statistically discernible effects in physical exertion, maximum pain intensity, pain-related work interference, or number of pain regions. We found a significant reduction of MSP-related sickness absence in the intervention compared to the control group [-0.48 days per month ( $95 \%$ confidence interval $(\mathrm{CI}),-0.8--0.1]$. We found no significant effects in NRF or involvement of employees, but self-efficacy was reduced in the intervention compared to the control group [-0.2 (95\% CI, $-0.3--0.0)]$.

Conclusion This 20-week training for a participatory ergonomic intervention in childcare workers did not show effects on physical exertion and MSP, but was both feasible and effective in reducing MSP-related sickness absence.

Key terms MSD; musculoskeletal disease; musculoskeletal disorder; RCT; sickness absence; workplace intervention.

There are more than 671 million children under five years of age in the world today. Given that labor force participation rates exceed $60 \%$ globally, a large number of these children need some sort of non-parental care during the day (1). In particular womens' labor force participation is highly depended on availability of high quality childcare (2). Thus, there is a great need for healthy and fit childcare workers. However, childcare workers generally appear to suffer from poor health (3,
4). Danish childcare workers report a high prevalence of musculoskeletal pain (MSP) and sickness absence (5). Preventive initiatives to improve health are, therefore, important for this occupational group (6). The workplace holds great potential for addressing these health issues and promoting longer working lives.

MSP is a main contributor to sickness absence (7), and work-related factors are among the most important intervention targets to prevent MSP and MSP-related

1 National Research Centre for the Working Environment, Lersø Parkallé 105, 2100 Copenhagen Ø, Denmark.

2 Amsterdam UMC, Vrije Universiteit Amsterdam, Department of Public and Occupational Health, Amsterdam Public Health Research Institute, van der Boechorststraat 7, 1081 BT, Amsterdam, The Netherlands.

Correspondence to: Charlotte Diana Nørregaard Rasmussen, National Research Centre for the Working Environment, Lersø Parkallé 105 , 2100 Copenhagen Ø, Denmark. [E-mail: cnr@nfa.dk] 
sickness absence (8). These factors particularly involve high physical workload [eg, physical exertion $(8,9)]$, which has been found to be prevalent among childcare workers $(5,10,11)$. The physical demands of working in childcare include the need to lift, carry, and support children in a range of activities, requiring several demanding body postures and movements, such as bending forward and twisting of the back and sitting on the floor (10). However, childcare work can also be mentally and emotionally exhausting and stressful for some individuals (12). Another important factor in those exposed to high physical work demands is the need for recovery (NFR) after a workday, which is greatest among workers who experience high levels of time pressure and physical work demands (13). Moreover, high NFR after work is associated with MSP (14) and increases the risk of subsequent sickness absence (15). Thus, there is a need for effective and feasible interventions to reduce high physical exertion during work and NFR after work, thereby preventing MSP and reducing sickness absence due to MSP among childcare workers.

Participatory ergonomics programs are commonly used as workplace interventions for prevention of MSP $(16,17)$. The involvement of workers in the process is essential as it ensures that participants take responsibility for and ownership of risk identification, solution development, and implementation of change (18), all of which is important for intervention effectiveness $(19,20)$. The participatory ergonomics process encourages workers to be involved in optimizing their own work routines, consequently decreasing work-related risk factors (21) and thereby improving their health (22). However, evidence on the effectiveness of participatory ergonomics for reducing physical exertion, MSP, NFR and MSP-related sickness absence is incomplete $(16,23-25)$.

Our aim of study was to investigate the effectiveness of a participatory ergonomic intervention at the workplace over 20 weeks in childcare workers on the primary outcomes physical exertion and MSP and the secondary outcomes MSP-related sickness absence, NFR, employee involvement, and self-efficacy. We hypothesized that the implementation of the 20 -week participatory ergonomic intervention would reduce physical exertion and MSP among childcare workers compared to usual practice (26).

\section{Methods}

Between August 2017 and July 2018, we conducted a two-arm, cluster-randomized controlled study with a waiting-list control. Clusters were formed based on childcare institutions and randomly assigned to two different arms (immediate versus delayed intervention, 20 weeks apart). This design yielded the possibility to offer the intervention to the control group after the intervention had been implemented in the intervention group, thereby decreasing the risk of hampering implementation due to logistical issues and reduced organizational commitment $(27,28)$. We published a study protocol prior to enrolling participants (26). The trial was prospectively registered (ISRCTN10928313). The Danish National Committee on Biomedical Research Ethics (ie, the local ethics committee of Frederiksberg and Copenhagen) has evaluated a description of the study and concluded that, according to Danish law as defined in Committee Act $\S 2$ and $\S 1$, the intervention described need not be reported to the local ethics committee (Ref number: 16048606). We obtained written, informed consent from all participants before they enrolled in the trial.

\section{Participants}

Details regarding the recruitment procedures of workplaces (childcare institutions) and workers have been reported elsewhere (26). In short, the childcare institutions were recruited with assistance from the municipality of Copenhagen after presenting the project at a meeting of region managers. Eligibility criteria for participation in the study for the institutions were: (i) childcare for children aged $0-3$ years, (ii) $\geq 9$ employees (childcare workers), and (iii) no recent (within the previous year) participation in an ergonomics course from the Work Environment Consultancy of Copenhagen. There were 29 eligible institutions in total, and all their childcare workers were eligible for participation. Since this was an organizational intervention, all childcare workers were expected to participate. Due to the design of the intervention, we only included those workers who we suspected would be at the workplace during the intervention period, meaning that if we knew that a worker would end her/his employment during the study period, he/she was not included in our study sample for the trial (ie, the evaluation) but could still participate in the activities at work.

\section{Randomization and blinding}

For practical reasons, the baseline measurement took place after randomization but before any intervention treatment. This was done because the workplaces needed to plan the workshops that were carried out as part of the intervention in advance. All childcare institutions (clusters) gave initial agreement to participate before we performed the randomization. Since the intervention was group-based, and to avoid contamination between workers, the randomization was performed across clusters at the childcare institution level balanced on size. 
The study was dimensioned to enroll approximately 200 workers. An independent data manager performed the randomization by using a computer-generated randomization using the SAS statistical software for Windows 9.4 (SAS Institute, Cary, NC, USA) developed by an independent statistician. Blinding of participants was not possible due to the nature of the intervention. However, data collection was performed using text messages and all persons collecting/handling data were blinded to group allocation.

\section{Procedures}

All childcare workers in the intervention group were involved in the participatory ergonomics process. Ergonomic consultants from the Work Environment Consultancy of Copenhagen (occupational therapists and physiotherapists) guided the process. The participatory ergonomic process followed 6 steps: (i) identification of risk factors, (ii) analysis of risk factors, (iii) solution building, (iv) prototype implementation, (v) prototype evaluation, and (vi) solution adoption. A main feature of this participatory ergonomics intervention was the integration with the core work tasks as previously recommended for improving implementation $(6,29)$. The first workshop lasted 3 hours and was conducted in week 2 . The two follow-up meetings lasted 1.5 hours each, the first meeting was conducted approximately six weeks after the first workshop and the final meeting was conducted approximately four weeks after the second meeting. In addition, each workplace was offered one ergonomic consultant visit. We observed a selection of workshops and assessed the content against prespecified criteria to check the workshop content was as intended (fidelity). Those in the control group followed usual practice from baseline to 20 -week follow-up. This group received the intervention after the 20 -week follow-up. More information about the intervention can be found in the study protocol (26).

\section{Outcomes and measurements}

Data were collected at 4, 8, 12, 16, and 20 weeks after randomization by use of electronic questionnaires sent via text message to participants' mobile phone (a link to a questionnaire in survey exact). The two primary outcomes of this study were self-rated physical exertion measured on a $0-10$ Likert scale (30) and MSP, measured as: (i) maximal pain intensity [0-10 on a numeric rating scale (NRS)] in any one of eight body regions (low back, neck, shoulders, knees, elbows, hands, hips, feet/ankles), (ii) number of pain regions (calculated as number of pain regions with an episode of pain (defined as $>1$ day with pain in a body region and with an intensity of $\geq 3$ on the NRS), and (iii) pain-related work inter- ference (days in the previous four weeks with pain that limits ability to do the work). Secondary outcomes were: (i) self-reported sickness absence due to MSP (days) (31) measured by questionnaire every four weeks from baseline to week 20; (ii) self-efficacy (32) measured by questionnaire at baseline and at week 20; (iii) NFR (33, 34) measured by questionnaire at baseline and at week 20; and (iv) employee involvement (35) measured by questionnaire at baseline and at week 20 .

\section{Process measures - changes in work}

At week 20, the intervention group was asked to score statements about changes in work adapted from Nielsen \& Randall's framework (36) about implementation, which was developed specifically for organizational level occupational health interventions. The statements posed were: (i) Through the implementation of the intervention, we finally get to straighten up some bad work methods that we had accepted; and (ii) New procedures have been introduced after the implementation of the intervention. The answer categories were on a 5-point Likert-type scale, from strongly disagree to strongly agree.

\section{Statistical analyses}

A sample of 192 participants (96 per group) corresponding to approximately 16 clusters in total was required to ensure $80 \%$ power to statistically demonstrate a relevant effect in physical exertion of 1 point (20). We estimated the effect of the intervention on the primary outcome using a mixed model for repeated measures. We treated time as a categorical variable (week $4,8,12,16$, and 20 ) and included group $\times$ time interactions to determine treatment effects at each time point. In addition, we took into account the possible differences between the groups at baseline. For this, a model was developed in which the treatment variable was not part of the model, but its interaction with time was (37). We set statistical significance at $\mathrm{P}<0.05$ for a 2 -sided test. The primary analysis was by intention-to-treat, including all eligible randomized participants who provided follow-up data. We compared demographic characteristics between dropouts and completers.

\section{Results}

Figure 1 shows the flowchart of the trial. Of 222 eligible workers from 16 workplaces, $190(86 \%)$ wanted to participate and provided baseline data; 32 were excluded for lack of data. In total, 96 and 94 childcare workers were randomized to the intervention and control groups, respectively. After the 20 -week intervention 


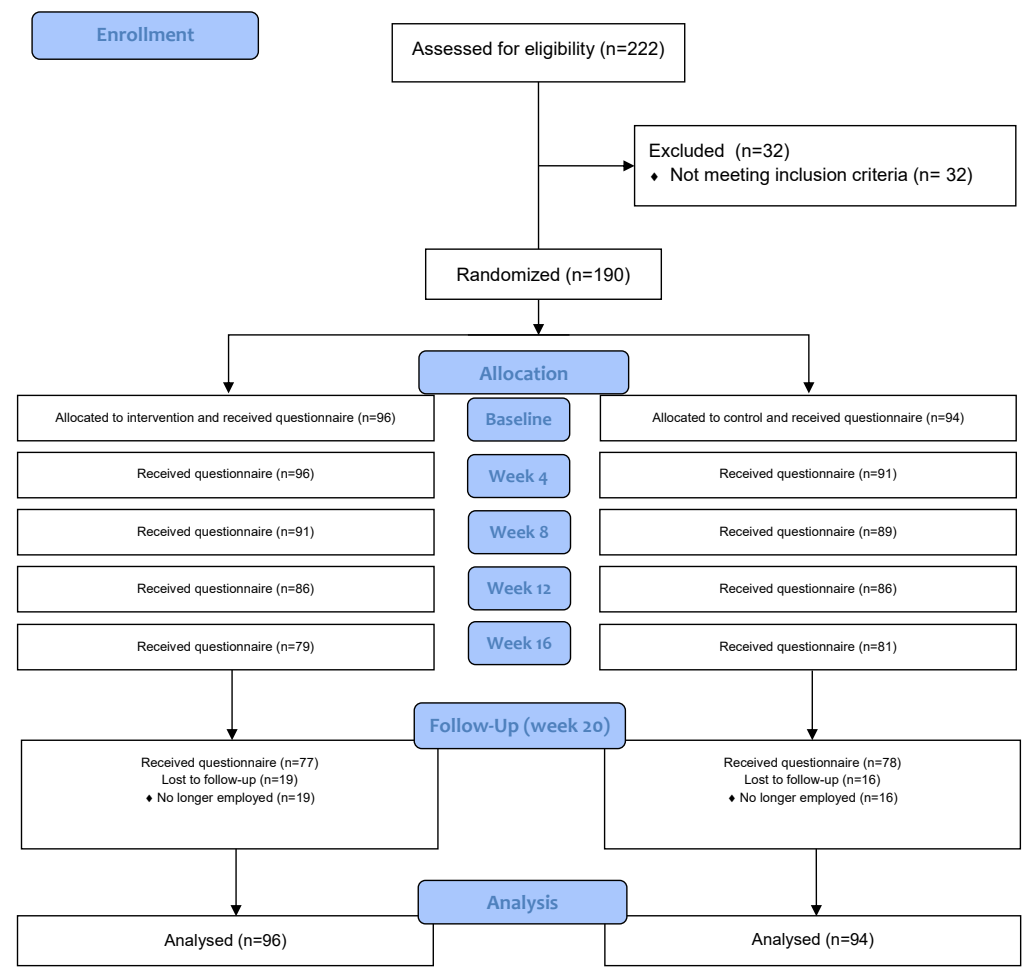

Figure 1. Consort flow diagram.

period, there were $19(20 \%)$ and $16(17 \%)$ workers lost to follow-up in the intervention and control groups, respectively. Table 1 shows baseline characteristics of the workers in both groups. There was a slight difference between the two groups with respect to gender. However, other demographic variables were similar. For both the primary and secondary outcomes there were some differences between the groups at baseline. We controlled for this difference in the statistical analysis by including baseline data of the respective variables in the model.

There were small differences in baseline characteristics between dropouts and completers. Dropouts were younger than the completers (28 versus 39 years). On other baseline characteristics the two groups were similar (data not shown).

\section{Process measures}

Dose delivered and dose received. The intervention was delivered by three ergonomic consultants from the Work Environment Consultancy of Copenhagen. All planned activities were delivered (table 2). In total, $88 \%, 70 \%$ and $62 \%$ of the workers participated in the first, second and third workshops, respectively. In addition, 43 (45\%) of the workers participated in all three workshops, 32 (33\%) participated in two workshops, 17 (18\%) participated in only one workshop, while four (4\%) did not participate in any of the workshops (data not shown).
The reasons for not participating in the workshops were employment ceased, vacation, leave, sickness absence or other/unknown.

Appraisal of intervention. Most participants were satisfied with the intervention $(78 \%)$ and found it relevant $(82 \%)$. In addition, nearly all (92\%) of the participants considered the intervention to be relevant for other childcare institutions (data not shown).

Changes in work. After implementation of the intervention, $58 \%$ of the participants agreed they had finally addressed some bad work methods they had previously accepted, and $50 \%$ agreed that new procedures had been introduced.

Intervention effects. Table 3 shows the intervention effects. At week 20, there were no statistically significant effects in physical exertion, maximum pain intensity, pain-related work interference, or number of pain regions. However, the estimates in mean treatment effect between groups at week 20 showed a small reduction in physical exertion and maximum pain intensity in the intervention group.

We found statistically significant effects in the intervention group on reduction of sickness absence due to MSP at week 20 compared to the control group. This corresponded to an intervention effect after 20 weeks for sickness absence due to MSP of -0.4 days per month [ $95 \%$ confidence interval $(\mathrm{CI}),-0.8--0.1]$. 
Table 1. Baseline characteristics.[SD=standard deviation.]

\begin{tabular}{lcclcr}
\hline & \multicolumn{2}{c}{$\begin{array}{c}\text { Intervention group } \\
(\mathrm{N}=96)\end{array}$} & & \multicolumn{2}{c}{$\begin{array}{c}\text { Control group } \\
(\mathrm{N}=94)\end{array}$} \\
\cline { 2 - 3 } \cline { 5 - 6 } & Mean (SD) & $\mathrm{N}(\%)$ & & Mean (SD) & $\mathrm{N}(\%)$ \\
\cline { 2 - 3 } Age (years) & $37(12.2)$ & & & $38(11.5)$ & \\
Gender (female) & & $78(81)$ & & $88(94)$ \\
Ethnicity (born in Denmark) & & $87(91)$ & & $77(82)$ \\
Smokers & & $26(27)$ & & $19(20)$ \\
Body mass index $\left(\mathrm{kg} / \mathrm{m}^{2}\right)$ & $25.7(5.2)$ & & & $25.0(5.9)$ & \\
\hline
\end{tabular}

Table 2. Participants in workshop.

\begin{tabular}{lccc}
\hline $\begin{array}{l}\text { Intervention } \\
\text { activities }\end{array}$ & \multicolumn{2}{c}{ Dose delivered } & $\begin{array}{c}\text { Dose received } \\
(\mathrm{N}=96)\end{array}$ \\
\cline { 2 - 4 } & Planned & Delivered (\%) & $\mathrm{N}(\%)$ \\
\hline Workshop 1 & 8 & 100 & $84(88)$ \\
Workshop 2 & 8 & 100 & $67(70)$ \\
Workshop 3 & 8 & 100 & $59(62)$ \\
\hline
\end{tabular}

At week 20, there were no significant effects in NFR or involvement of employees. However, there was a statistically significant reduction in self-efficacy of -0.2 (95\% CI, $-0.3--0.0)$ in the intervention compared to control group.

\section{Discussion}

We hypothesized that the implementation of the 20-week participatory ergonomic intervention would reduce physical exertion and MSP among childcare workers compared to usual practice. This hypothesis was not confirmed. Nevertheless, the participatory ergonomic intervention was both feasible and effective in reducing MSP-related sickness absence.

Our findings contrast with a systematic review concluding that participatory ergonomics was effective in reducing MSP (16). However, the results obtained from our study are in accordance with other randomized controlled trials, reporting that participatory ergonomics was not effective in reducing $\operatorname{MSP}(24,38)$.

By introducing participatory ergonomics, we aimed to minimize risk factors for MSP at work and improve the work tasks perceived as physically demanding. After the intervention, no significant effect was found for physical exertion or MSP when comparing the intervention with the control groups. In addition to these findings, we did not find any significant effects on NFR. According to our program logic, due to the participatory nature of the intervention, we expected the intervention to have an effect on self-efficacy and employee involvement (26). However, this was not the case. On the contrary, we found a small reduction of 0.15 on a scale from $0-4$ in self-efficacy in the intervention group. It is hard to interpret if this change is an intervention effect or just a chance finding. Furthermore, we question whether such a small reduction is of any practical relevance.

When an intervention does not show an effect on the primary outcomes, it is important to consider whether this is a theory or implementation failure $(29,39,40)$. With respect to implementation, all intervention workshops were successfully delivered. However, the dose received decreased over time, resulting in only $62 \%$ of the participants participating in the last workshop. This number, however, is comparable to other participatory ergonomics interventions (41). In addition, the measures

Table 3. Intervention effects on physical exertion, pain-related work interference, number of pain regions, maximum pain intensity, and sickness absence due to musculoskeletal pain (MSP), self-efficacy, need for recovery and employee involvement. [SE=standard error; $\mathrm{Cl}=$ confidence interval]

\begin{tabular}{|c|c|c|c|c|c|c|c|c|}
\hline \multirow[t]{2}{*}{ Variable } & \multirow[t]{2}{*}{ Time } & \multicolumn{2}{|c|}{ Intervention group } & \multicolumn{2}{|c|}{ Control group } & \multicolumn{3}{|c|}{ Mean treatment difference between group } \\
\hline & & $\mathrm{N}$ & Estimate (SE) & $\mathrm{N}$ & Estimate (SE) & Estimate (SE) & $95 \% \mathrm{Cl}$ & P-value \\
\hline \multicolumn{9}{|l|}{ Primary outcomes } \\
\hline \multirow{2}{*}{ Physical exertion (0-10) } & Baseline & 96 & $5.6(1.8)$ & 94 & $6.2(1.6)$ & & & \\
\hline & Week 20 & 61 & $5.5(2.0)$ & 61 & $6.1(1.9)$ & $-0.2(0.3)$ & $-0.8-0.4$ & 0.45 \\
\hline \multirow[t]{2}{*}{ Pain-related work interference (days 0-28) } & Baseline & 95 & $2.3(5.2)$ & 94 & $4.7(7.70)$ & & & \\
\hline & Week 20 & 61 & $3.7(6.9)$ & 60 & $4.6(7.55)$ & $0.2(1.2)$ & $-2.1-2.5$ & 0.59 \\
\hline \multirow{2}{*}{ Number of pain regions $(0-8)$} & Baseline & 95 & $2.2(1.7)$ & 94 & $2.6(1.83)$ & & & \\
\hline & Week 20 & 61 & $2.2(2.0)$ & 60 & $2.5(2.09)$ & $0.1(0.2)$ & $-0.4-0.5$ & 0.84 \\
\hline \multirow[t]{2}{*}{ Maximum pain intensity (0-10) } & Baseline & 95 & $5.4(2.30)$ & 94 & $5.9(2.8)$ & & & \\
\hline & Week 20 & 61 & $5.2(2.7)$ & 60 & $5.6(3.2)$ & $-0.1(0.4)$ & $-0.9-0.7$ & 0.73 \\
\hline \multicolumn{9}{|l|}{ Secondary outcomes } \\
\hline \multirow[t]{2}{*}{ Sickness absence due to MSP (days 0-28) } & Baseline & 94 & $0.4(2.3)$ & 94 & $0.7(3.2)$ & & & \\
\hline & Week 20 & 61 & $0.1(0.4)$ & 60 & $0.4(1.1)$ & $-0.4(0.2)$ & $-0.6--0.1$ & 0.01 \\
\hline \multirow[t]{2}{*}{ Self-efficacy (0-4) } & Baseline & 96 & $3.3(0.5)$ & 94 & $3.4(0.5)$ & & & \\
\hline & Week 20 & 62 & $3.3(0.6)$ & 67 & $3.4(0.5)$ & $-0.2(0.1)$ & $-0.3--0.0$ & 0.01 \\
\hline \multirow[t]{2}{*}{ Need for recovery $(0-100)$} & Baseline & 96 & $60.94(29.20$ & 94 & 63.12 (26.98) & & & \\
\hline & Week 20 & 62 & $62.37(31.21)$ & 67 & $64.43(25.28)$ & $1.30(2.41)$ & $-3.45-6.04$ & 0.59 \\
\hline \multirow{2}{*}{ Employee involvement (0-100) } & Baseline & 96 & 73.09 (17.33) & 94 & 66.49 (16.35) & & & \\
\hline & Week 20 & 62 & $74.29(15.02)$ & 67 & 70.06 (14.66) & 1.94 (1.91) & $-1.81-5.69$ & 0.31 \\
\hline
\end{tabular}


regarding changes in work showed that $50-58 \%$ of the participants said the intervention resulted in changes in their work. This number might point towards implementation failure, since only half of the childcare workers said that changes had been made. In general, many ergonomic intervention studies lack information about implementation $(17,42)$. In our study, we have also gathered information about specific work exposures by objective measurements. However, there is a need for a deeper investigation of specific exposures related to the intervention. This is out of the scope of this paper but will be reported in a separate paper (26).

With respect to theory failure, one reason may be related to difficulties in evaluating participatory interventions. Due to the participatory approach, we do not know much about the actual content of a participatory ergonomic intervention, eg, risk identification or solution development, which then becomes a black box (43). Therefore it is important to consider whether the chosen outcomes are the most optimal for evaluating the effectiveness of participatory ergonomics interventions.

The participatory ergonomic intervention was effective in reducing MSP-related sickness absence. This finding is in accordance with another study among employees in pre-schools from Denmark investigating a participatory organizational level intervention with a focus on the core task at work (6). A main feature of our participatory ergonomics intervention was also the integration with the core work tasks. This was, in particular, how to make the children more independent of active assistance from the childcare workers (eg, climbing up in the crib and changing table, getting outdoor clothes on) so that the physical work demands could be decreased among the childcare workers. The intervention effect on MSP-related sickness absence could therefore be explained by the children requiring less assistance, possibly making the childcare worker better able to work with the same level of MSP. The reduction in MSP-related sickness absence after 20 weeks was very high (corresponded to a reduction of $88 \%$ from baseline to follow-up) and thus of substantial importance for the workplace. However, we do not know whether it was the focus on the core tasks at work that resulted in the reduced MSP-related sickness absence or if other mechanisms were at work. This should be investigated by further analyses of the process evaluation data from the study.

Another main finding of the study was the high feasibility of implementing the participatory ergonomic intervention in terms of high delivery of the intervention and the moderate dose received. This is possibly also related to the focus on the core work tasks, making the intervention more relevant for the childcare workers, and not considering sideline activities with limited relevance (29). This was also seen in the positive appraisal of the intervention with nearly all (92\%) of the participants considering the intervention to be relevant for other childcare institutions

\section{Strengths and limitations of the study}

The cluster-randomized controlled trial design is a methodological strength since it minimized the risk of contamination between the intervention and reference group and reduced the risk for bias. Repeated measurements with short recall were used to measure study outcomes and we used measures that have all been found to have a reliable validity $(30,31)$. Another strength is that consultants delivered the intervention and were not involved in the evaluation. Lastly, this study was executed in real working-life settings, which makes it easier to generalize the effects to similar workplaces.

A limitation of this study is the loss to follow-up rates on the primary and secondary outcomes found after 20 weeks. Unfortunately, loss to follow-up is a common problem among prevention studies (44). Checking our data for selective dropout revealed that dropouts did not differ from completers. Also, since this is an organizational intervention, it did not focus on individual workers. Thus, individual randomization was not feasible. Moreover, due to the interventional trial design, participants were not blinded to group allocation. Finally a limitation is that we did not measure changes in work very well.

\section{Concluding remarks}

A 20-week workplace participatory ergonomic intervention in childcare workers did not show effects on the primary outcomes of physical exertion and MSP, but was both feasible and effective in reducing MSP-related sickness absence.

\section{Acknowledgements}

We would like to acknowledge consultants Vibeke Andersen and Cornelia Strøh from the Work Environment Consultancy of Copenhagen for their valuable help in the development and planning of the study. In addition, we would like to thank the team involved in the TOY project at the National Research Centre for The Working Environment for their valuable contributions in planning of the study and collecting of data and providing feedback in discussions of the study.

\section{Funding}

The study was externally funded by the Danish Work- 
ing Environment Research Fund (grant no. 2-2016-03 20165101186).

\section{References}

1. Samman E, Presler-Marshall E, Jones N, Bhatkal T, Melamed C, Stavropoulou M et al. Women's work Mothers, children and the global childcare crisis. In: Institute OD, editor. London, United Kingdom: Overseas Development Institute; 2016.

2. Conroy T. The kids are alright: working women, schedule flexibility and childcare. Reg Stud 2019;53(2):261-71. https://doi.org/10.1080/00343404.2018.1462478.

3. Ward DS, Vaughn AE, Hales D, Viera AJ, Gizlice Z, Bateman LA et al. Workplace health and safety intervention for child care staff: Rationale, design, and baseline results from the CARE cluster randomized control trial. Contemp Clin Trials 2018 May;68:116-26. https://doi.org/10.1016/j. cct.2018.02.018.

4. Linnan L, Arandia G, Bateman LA, Vaughn A, Smith N, Ward D. The Health and Working Conditions of Women Employed in Child Care. Int J Environ Res Public Health 2017 Mar;14(3):283. https://doi.org/10.3390/ ijerph14030283.

5. Arbejdsmiljø DNFf. Arbejdsmiljø og Helbred i Danmark. http:// www arbejdsmiljoforskning dk [Internet]. 2016 1/29/2016. Available from: http://www.arbejdsmiljoforskning.dk.

6. Framke E, Sørensen OH, Pedersen J, Rugulies R. Effect of a participatory organizational-level occupational health intervention on short-term sickness absence: a cluster randomized controlled trial. Scand J Work Environ Health 2016 May;42(3):192-200. https://doi.org/10.5271/ sjweh.3559.

7. Fernandes RC, Burdorf A. Associations of multisite pain with healthcare utilization, sickness absence and restrictions at work. Int Arch Occup Environ Health 2016 Oct;89(7):1039-46. https://doi.org/10.1007/s00420-0161141-7.

8. Andersen LL, Fallentin N, Thorsen SV, Holtermann A. Physical workload and risk of long-term sickness absence in the general working population and among blue-collar workers: prospective cohort study with register follow-up. Occup Environ Med 2016 Apr;73(4):246-53. https://doi. org/10.1136/oemed-2015-103314.

9. Andersen LL, Clausen T, Persson R, Holtermann A. Dose-response relation between perceived physical exertion during healthcare work and risk of long-term sickness absence. Scand J Work Environ Health 2012 Nov;38(6):582-9. https://doi.org/10.5271/sjweh.3310.

10. Gratz RR, Claffey A, King P, Scheuer G. The physical demands and ergonomics of working with young children. Early Child Dev Care 2002;172(6):531-7. https://doi. org/10.1080/03004430215109
11. Grant KA, Habes DJ, Tepper AL. Work activities and musculoskeletal complaints among preschool workers. Appl Ergon 1995 Dec;26(6):405-10. https://doi. org/10.1016/0003-6870(95)00057-7.

12. McGrath BJ. Identifying health and safety risks for childcare workers. AAOHN J 2007 Aug;55(8):321-5. https://doi. org/10.1177/216507990705500804.

13. Sluiter JK, van der Beek AJ, Frings-Dresen MH. The influence of work characteristics on the need for recovery and experienced health: a study on coach drivers. Ergonomics 1999 Apr;42(4):573-83. https://doi. org/10.1080/001401399185487.

14. Gawke JC, Gorgievski MJ, van der Linden D. Office work and complaints of the arms, neck and shoulders: the role of job characteristics, muscular tension and need for recovery [-OA.]. J Occup Health 2012;54(4):323-30. https://doi. org/10.1539/joh.11-0152-OA.

15. de Croon EM, Sluiter JK, Frings-Dresen MH. Need for recovery after work predicts sickness absence: a 2-year prospective cohort study in truck drivers. J Psychosom Res 2003 Oct;55(4):331-9. https://doi.org/10.1016/S00223999(02)00630-X.

16. Rivilis I, Van Eerd D, Cullen K, Cole DC, Irvin E, Tyson $\mathrm{J}$ et al. Effectiveness of participatory ergonomic interventions on health outcomes: a systematic review. Appl Ergon 2008 May;39(3):342-58. https://doi.org/10.1016/j. apergo.2007.08.006.

17. van der Beek AJ, Dennerlein JT, Huysmans MA, Mathiassen SE, Burdorf A, van Mechelen W et al. A research framework for the development and implementation of interventions preventing work-related musculoskeletal disorders. Scand J Work Environ Health 2017 Nov;43(6):526-39. https://doi. org/10.5271/sjweh.3671.

18. van Eerd D, Cole D, Irvin E, Mahood Q, Keown K, Theberge $\mathrm{N}$ et al. Process and implementation of participatory ergonomic interventions: a systematic review. Ergonomics 2010 Oct;53(10):1153-66. https://doi.org/10.1080/0014013 9.2010 .513452 .

19. Durlak JA, DuPre EP. Implementation matters: a review of research on the influence of implementation on program outcomes and the factors affecting implementation. Am J Community Psychol 2008 Jun;41(3-4):327-50. https://doi. org/10.1007/s10464-008-9165-0.

20. Nielsen K, Randall R, Albertsen K. Participants' appraisals of process issues and the effects of stress management interventions. J Organ Behav 2007;28(6):793-810. https:// doi.org/10.1002/job.450.

21. Wilson JR. HAINES HM. Participatory ergonomics. In: Salvendy G, editor. Handbook of Human Factors and Ergonomics. 2nd edn ed: Wiley; 1997. p. 490-513.

22. Haines H, Wilson JR, Vink P, Koningsveld E. Validating a framework for participatory ergonomics (the PEF). Ergonomics 2002 Mar;45(4):309-27. https://doi. org/10.1080/00140130210123516.

23. Pehkonen I, Takala EP, Ketola R, Viikari-Juntura E, 
Leino-Arjas P, Hopsu L et al. Evaluation of a participatory ergonomic intervention process in kitchen work. Appl Ergon 2009 Jan;40(1):115-23. https://doi.org/10.1016/j. apergo.2008.01.006.

24. Haukka E, Leino-Arjas P, Viikari-Juntura E, Takala EP, Malmivaara A, Hopsu L et al. A randomised controlled trial on whether a participatory ergonomics intervention could prevent musculoskeletal disorders. Occup Environ Med 2008 Dec;65(12):849-56. https://doi.org/10.1136/ oem.2007.034579.

25. Driessen MT, Proper KI, van Tulder MW, Anema JR, Bongers PM, van der Beek AJ. The effectiveness of physical and organisational ergonomic interventions on low back pain and neck pain: a systematic review. Occup Environ Med 2010 Apr;67(4):277-85. https://doi.org/10.1136/ oem.2009.047548.

26. Rasmussen CD, Hendriksen PR, Svendsen MJ, Ekner D, Hansen K, Sørensen $\mathrm{OH}$ et al. Improving work for the body - a participatory ergonomic intervention aiming at reducing physical exertion and musculoskeletal pain among childcare workers (the TOY-project): study protocol for a wait-list cluster-randomized controlled trial. Trials 2018 Jul;19(1):411. https://doi.org/10.1186/s13063-018-2788-z.

27. Brown CA, Lilford RJ. The stepped wedge trial design: a systematic review. BMC Med Res Methodol 2006 Nov;6(1):54. https://doi.org/10.1186/1471-2288-6-54.

28. Mdege ND, Man MS. Taylor nee Brown CA, Torgerson DJ. Systematic review of stepped wedge cluster randomized trials shows that design is particularly used to evaluate interventions during routine implementation. J Clin Epidemiol 2011;64(9):936-48. https://doi.org/10.1016/j. jclinepi.2010.12.003.

29. Kristensen TS. Intervention studies in occupational epidemiology. Occup Environ Med 2005 Mar;62(3):205-10. https://doi.org/10.1136/oem.2004.016097.

30. Borg GA. Physical performance and perceived exertion: Gleerup Lund; 1962.

31. Burdorf A, Post W, Bruggeling T. Reliability of a questionnaire on sickness absence with specific attention to absence due to back pain and respiratory complaints. Occup Environ Med 1996 Jan;53(1):58-62. https://doi.org/10.1136/ oem.53.1.58.

32. Schwarzer R, Bässler J, Kwiatek P, Schröder K, Zhang JX. The Assessment of Optimistic Self beliefs: Comparison of the German, Spanish, and Chinese Versions of the General Self efficacy Scale. Appl Psychol 1997;46(1):69-88. https:// doi.org/10.1111/j.1464-0597.1997.tb01096.x.

33. van Veldhoven M, Broersen S. Measurement quality and validity of the "need for recovery scale". Occup Environ Med 2003 Jun;60 Suppl 1:i3-9. https://doi.org/10.1136/ oem.60.suppl_1.i3.
34. Garde AH, Albertsen K, Nabe-Nielsen K, Carneiro IG, Skotte J, Hansen SM et al. Implementation of self-rostering (the PRIO-project): effects on working hours, recovery, and health. Scand J Work Environ Health 2012 Jul;38(4):314-26. https://doi.org/10.5271/sjweh.3306.

35. Clausen T, Madsen IE, Christensen KB, Bjorner JB, Poulsen OM, Maltesen T et al. The Danish Psychosocial Work Environment Questionnaire (DPQ): Development, content, reliability and validity. Scand J Work Environ Health 2019 Jul 1;45(4):356-69. https://doi.org/10.5271/sjweh.3793.

36. Nielsen K, Randall RJEJoW, Psychology O. Opening the black box: Presenting a model for evaluating organizational-level interventions. European Journal of Work and Organizational Psychology 2013;22(5):601-17.

37. Twisk J, Bosman L, Hoekstra T, Rijnhart J, Welten M, Heymans M. Different ways to estimate treatment effects in randomised controlled trials. Contemp Clin Trials Commun 2018 Mar;10:80-5. https://doi.org/10.1016/j. conctc.2018.03.008.

38. Driessen MT, Proper KI, Anema JR, Knol DL, Bongers PM, van der Beek AJ. The effectiveness of participatory ergonomics to prevent low-back and neck pain--results of a cluster randomized controlled trial. Scand J Work Environ Health 2011 Sep;37(5):383-93. https://doi.org/10.5271/ sjweh.3163.

39. Oakley A, Strange V, Bonell C, Allen E, Stephenson J; RIPPLE Study Team. Process evaluation in randomised controlled trials of complex interventions. BMJ 2006 Feb;332(7538):413-6. https://doi.org/10.1136/ bmj.332.7538.413.

40. Jaegers L, Dale AM, Weaver N, Buchholz B, Welch L, Evanoff B. Development of a program logic model and evaluation plan for a participatory ergonomics intervention in construction. Am J Ind Med 2014 Mar;57(3):351-61. https://doi.org/10.1002/ajim.22249.

41. Ferm L, Rasmussen CD, Jørgensen MB. Operationalizing a model to quantify implementation of a multi-component intervention in a stepped-wedge trial. Implement Sci 2018 Feb;13(1):26. https://doi.org/10.1186/s13012-018-0720-2.

42. Takala EP. Ergonomic interventions and prevention-a need for better understanding of implementation. Scand J Work Environ Health. 2018 Mar 1;44(2):111-12. https://doi. org/10.5271/sjweh.3710.

43. Rasmussen CD, Lindberg NK, Ravn MH, Jørgensen MB, Søgaard K, Holtermann A. Processes, barriers and facilitators to implementation of a participatory ergonomics program among eldercare workers. Appl Ergon 2017 Jan;58:491-9. https://doi.org/10.1016/j.apergo.2016.08.009.

44. Galea S, Tracy M. Participation rates in epidemiologic studies. Ann Epidemiol 2007 Sep;17(9):643-53. https://doi. org/10.1016/j.annepidem.2007.03.013.

Received for publication: 29 August 2019 